\title{
RESEARCH ON THE SUBJECT OF NUTRITION IN PHYSICAL EFFORT DETERMINATION
}

\author{
Fabiana MARTINESCU \\ "Romanian-German" University of Sibiu, Romania, \\ fabiana.martinescu@yahoo.com
}

\begin{abstract}
Living organisms are in close dependence with the environment.
There is also a permanent exchange of substance, energy and information between the human body and the environment, an exchange that underlies the development of all biological processes. In the normal biological processes, the essential environmental factors compete, among which we mention the air, water and food. The importance of food (lat. alimentum - aliment)consists of the intake of nutrients necessary for all life processes.

The substances from food are generically described by the term "nutrient principles" or "food principles", often being used the term "nutrients". Among nutrients, depending on their amount in the food products and the physiological and biochemical role, there are the macronutrients (carbohydrates, lipids and protides), micronutrients (mineral compounds of biological interest and vitamins) as well as other nutrients (water, fibres, biologically-active substances).
\end{abstract}

\section{Keywords: nutrition, bodybuilding, nutrient, metabolism}

\section{Introduction}

First and foremost, not all calories are created equal [1].

Nutrient principles (nutrients) vary in terms of composition and amount from one aliment to another. For this reason, ensuring the necessary nutrients is done by a balanced and complex diet.

Food is processed or unprocessed substances intended for human nutrition and designed to satisfy the food needs and the energy needs to maintain the vital functions, ensure growth and development, maintain capacities for physical and psychical activities. Nonetheless, food consumption involves only oral administration.

\section{Nutrition}

Food groups include vegetables and fruit, grain products, milk and alternatives, meat and alternatives, plus a small amount of added fats and oils. Together healthy eating and physical activity can help reduce the risk of obesity and prevent chronic diseases such as type 2 diabetes, heart disease, certain types of cancer and osteoporosis[2]. Medication - refers to products used for diagnosis, with prophylactic or therapeutic purposes in relation to various physical or psychical disorders. Drug administration may be done on the enteral (digestive) or parenteral routes. Drug administration seeks specific goals which target the change of certain physical or behavioural activities.

Dietary supplements, sometimes called "nutritional supplements" are concentrated sources of nutrients or of other substances, with nutritional or physiological effect, being found separately or in combination, which complete a diet. Commercially, they can be found as tablets, drops, capsules or other similar forms which contain vitamins, minerals, bioactive substances (from plant extracts). 
Carbohydrates are natural chemical compounds, present in the plant and animal world. In their composition there are the socalled "ternary bioelements"; carbon; hydrogen and oxygen, which structurally define simple carbohydrates, such as -ose type (monosaccharide); e.g.: glucose, fructose, galactose and riboseetc. There are carbohydrate compounds with a more complex structure called oxides, of which, in larger quantities in nature, there are the polyholosides (poliglucides), e.g.: complex carbohydrates (starch, cellulose), fructants and so on. High carbohydrate diets are typically thought to be the athletic performance standard. However, like protein, carbohydrate intake needs to be customized to the individual [3]. The class of oxides also includes the heterosides(glycosides) in which nitrogen, phosphorus and sulfur were detected. The compounds from the class of carbohydrates are also known as "sugars" or "carbohydrates" (with the choices of names such as: carbohydrates or hydrocarbons).

Lipids are compounds with a heterogeneous structure and various chemical properties, having two essential characteristics: hydrophobicity and insolubility in water. This class of compounds includes: simple lipids, e.g.: acylglycerols, sterides, etholides; complex lipids, e.g.: glycerophospholipids.

Lipids can be found in the various plant and animal food products and, of course, in the human body.

Protides are a large class of bioconstituents which have a ubiquitous distribution in the living world. In the plant and animal food products there are protide nutrients, entering thehuman body through nutrition. These nutrients, after metabolism, turn into bioconstituents of the human body.

In terms of their chemical composition, proteins constitute into two groups of compounds: simple proteins and complex proteins.

Proteins, are compounds of amino-acids. Amino-acids are the bricks of muscle construction. The lack of amino-acids materializes in a minimal or non-existing muscle growth. Amino-acids, once ingested, do not need digestion since they are directly sent in the blood flow for immediate use by the muscle cells. Aminoacids ensure $70 \%$ of the body's need for nitrogen.

Amino-acids are divided in two categories: essential amino-acids and non-essential amino-acids. Essential amino-acids are those that cannot be produced by the human body, being necessary to be ensured from proteins with complete amino-acid profile (animal protein) or from combinations of incomplete protein profile (usually vegetable proteins). There are 9 essential amino-acids and 13 non-essential aminoacids. Non-essential amino-acids can be produced by our own body from vitamins and other amino-acids.

Essential branched-chain amino acidsBCCAA's have a particular importance for athletes because they are metabolized in the muscles and not in the liver. After digestion, once the proteins have been "broken" into amino acids, they are used either to form new proteins, or to be consumed as energetic support.

Minerals are basic nutrients, which are essential for the proper functioning of all metabolic processes that occur in the body. We present some data referring to the necessary of some mineral elements for an adult organism, for example: sodium - 2,43,6 g/day; potassium 2-4 g/day; calcium 700-800 mg/day; magnesium 300-350 $\mathrm{mg} /$ day etc.

For adult body, the daily recommended input varies greatly from one vitamin to another. For the lipo-soluble vitamins, the values are presented in international units (UI), e.g. for vitamin A there is 4000-5000 UI/day; for vitamin D 200UI/day. For the water-soluble vitamins, the values are given in $\mathrm{mg}$, e.g.: vitamin $\mathrm{B}$, from $1,1-1,5$ $\mathrm{mg} /$ day; vitamin B7 (biotin) - 30-300 micrograms etc.

Water requirement of an adult body is 2500-3000 $\mathrm{ml} /$ day, of which approximately $300 \mathrm{ml}$ comes from the burning in the 
organism of the food ingested by exogenous inputs.

A large percentage of muscle tissue mass is water and dehydration results in decreases in muscle water content [4].

The energy released by the amounts of nutrients are numbered as follows: carbohydrates $-4,1 \mathrm{cal} / \mathrm{g}$; lipids 9,3 cal / $\mathrm{g}$; proteins $4,1 \mathrm{cal} / \mathrm{g}$.

Assessing the role of food in energetic genesis and the amount of energy released by various nutrients is considering their expression in calories or joules. For interconversion, the following relations are used: $1 \mathrm{cal}=4,184$ joules; 1 joule $=0,239$ calories.

Similar to other root vegetables, turnips, carrots, beetroot, and parsnips have a high water content and contain both simple and complex carbohydrates. They are a poor source of protein, but also contain important micronutrients and non-nutritive components. The antioxidant, $\beta$-carotene, is found in deep yellow/orange vegetables and fruits and dark green leafy vegetables. $\beta$-carotene is readily converted to Vitamin A, which plays any important role normal growth and development, immune system function, and vision [5].

In physiology, it is recognized that there is a certain minimum energy requirements, essential for vital functions, an opinion which led to the concept of basic energy requirements. This basic energy needs ensures the energetic status of the so-called basic metabolism. The basic energy requirements, conditioned by the basic metabolism, can be defined as the energy required by an individual who is in standby - in physical and mental rest - 24 hours after the last ingestion of food and under conditions of constant temperature (20$21^{\circ} \mathrm{C}$ ) of the ambient. For an adult, the necessary energy for a basic metabolism is of approximately 1 calorie / 1 kilogram of body weight and hour. Therefore, for a person weighting $70 \mathrm{~kg}$, the energy requirement is of about 1.680 calories / 24 hours. It is true that resistance training utilizes glycogen as its main fuel source [6].

\section{Food requirements}

The definition of food requirements requires the establishment of the amount of nutrients required by human consumption. Its relation is made to the individual body weight and to time. It is usually expressed in $\mathrm{g} /$ body $\mathrm{kg} /$ day. Thus, it is considered that, for an adult individual, the food requirements (daily energetic - caloric needs) given by the basic energy requirements through basic metabolism, together with the energy requirements of relationship, described by the energy surplus required in the thermoregulation, food incorporation and muscle effort process.

The food requirements of protides for an adult is considered to be $1,0-1,5 \mathrm{~g} /$ body weight / day. This represents approximately $11-13 \%$ of the caloric value of the daily ration. From the total amount of proteins, essential amino acids are basic nutrients. Therefore, for an adult, the essential amino acids intake should be $1 / 2$ of the total of proteins, and for a young organism (children) approximately $2 / 3$.

The food requirements of lipids. These are known especially as "calorie-dense substances". The requirements of lipids for an adult body is recommended to be of 1,0$2,0 \mathrm{~g} /$ body $\mathrm{kg} /$ day, representing $25-30 \%$ of the caloric value of daily ration.

The food requirements of carbohydrates, based on the ideal weight of an adult is estimated at 4,0-8,0 g/body $\mathrm{kg} / \mathrm{day}$, which is considered to be approximately $55-62 \%$ of the total caloric value of a daily ration. 
Table 1 Nutritional value of certain food

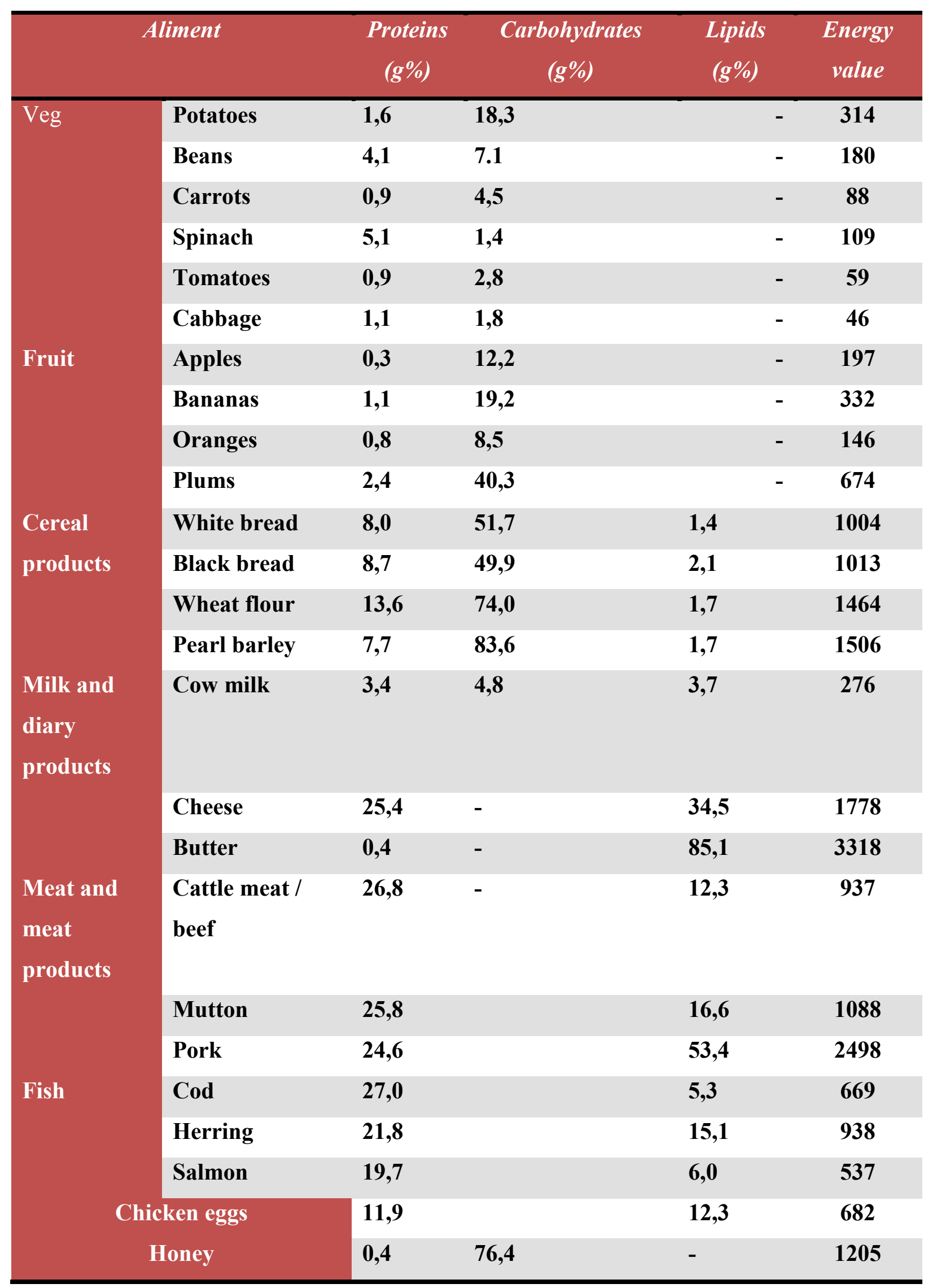


Conclusions: Undoubtedly, all nutrients are important for nutrition and a correct nutritional plan should include them all, but, as far as proteins are concerned, in terms of practicing bodybuilding and fitness, a more comprehensive discussion is required.

We consider that one of the terms most frequently used in bodybuilding is the term "protein". It is obvious that most of the people practicing bodybuilding, either of performance or as a way to relax, recognize that their diet should include that nutrient called protein, in larger quantities than those necessary to an individual who does not go to the gym and is not interested in muscle hypertrophy.

Proteins are more important for athletes in general and for bodybuilders in particular, because they are designed to prevent muscle catabolism and they stimulate muscle growth.

Beyond these basic information about "proteins", there are various questions that raise when you enter a shop for supplements and you ask yourself "which is the best protein that meets my needs and goals?" In order to have an answer to this question, you must definitely have some information that, once pieced out, will lead to the right answer.

The question whether high amounts of proteins are necessary to optimize body protein synthesis and to increase muscle strength and hypertrophy has been discussed for decades now; a debate that is also fueled by the increasingly higher number of manufacturing companies and the publicity that they do to their products. Proteins are the cornerstone of life and the main structural components of the body. Proteins contain 15\%nitrogen and they can be found in food. Proteins cannot be absorbed as such through the intestine into the blood. Therefore, during digestion, the body "breaks" the proteins into smaller pieces, which can be absorbed, called amino-acids. They have a plastic (construction) role in the body and they are not used as a source of energy. Over time, 22 types of amino-acids have been discovered, of which 8 are considered essential and the remaining 14 nonessential. Essential amino-acids are those that the human body cannot produce and therefore they must be supplied by food. All nutrients are important, but only proteins are the ones responsible for building muscles through the supply of nitrogen, much needed for growth, recovery and tissue repair. Muscle growth can be achieved through a correct planning of the number of daily meals and keeping a high quality of the meals. A number of 6-7 meals a day that contain proteins will ensure a constant flow of amino-acids to the blood and will help rebuild muscle tissue. When the amount of amino-acids is not enough, the body catabolizes the muscle tissue to ensure the amino-acids reserves. Studies have shown that a person's body that does not do physical activity such as bodybuilding needs approximately $0,8 \mathrm{~g}$ of protein for each kilogram of body weight (kg body weight). Moreover, studies revealed that for a person who practices bodybuilding, the need for recovery and muscle growth is much higher; therefore, the burn-up of 1,9-2 proteins/ $\mathrm{kg}$ body weight will ensure the optimal muscle recovery and hypertrophy.

However, it is caution is recommended when the protein burn-up is over $1 \mathrm{~g} / \mathrm{kg}$ body weight. High protein diets, without a proper electrolyte balance, namely a proper infusion of minerals into the blood, as well as good hydration may cause harmful metabolic products (uric acid) as a result of incomplete conversion of proteins into amino-acids. 


\section{References:}

1. Gerard Dente with Kevin J. Hopkins, Macrobolic Nutrition, Priming Your Body To Build Muscle \& Burn Fat, Basic Health Publications, Inc., USA, 2-3, 2004,

2. Health Canada. Eating Well with Canada's Food Guide http://www.healthcanada.gc.ca/foodguide

3. Leveritt M, Abernethy PJ: Effects of carbohydrate restriction on strength performance. $J$ Strength Cond Res 13:52-57, 1999

4. Costill DL, Cote R, Fink W: Muscle water and electrolytes following varied levels of dehydration in man. $J$ Appl Physiol 40:6-11, 1976

5. Grune T, Lietz G, Palou A, Ross AC, Stahl W, Tang G, Thurnham D, Yin SA, and Biesalski HK. Beta-carotene is an important vitamin A source for humans. J Nutr. 2010

6. MacDougall JD, Ray S, Sale DG, McCartney N, Lee P, Garner S: Muscle substrate utilization and lactate production. Can J Appl Physiol, 24:209-215, 1999. 